\title{
EARTHQUAKE SCENARIOS FOR THE CITIES OF SOFIA, ROUSSE, AND VRATSA
}

\author{
Dimcho Solakov, Stella Simeonova, Ludmil Christoskov, Irena \\ Aleksandrova, Iliana Popova, and Gergana Georgieva
}

\begin{abstract}
Global seismic hazard and vulnerability to earthquakes are increasing steadily as urbanization and development occupy more areas that are prone to effects of strong earthquakes. The uncontrolled growth of mega cities in highly seismic areas around the world is often associated with the construction of seismically unsafe buildings and infrastructures, and undertaken with an insufficient knowledge of the regional seismicity peculiarities and seismic hazard. The assessment of seismic hazard and generation of earthquake scenarios is the first link in the prevention chain and the first step in the evaluation of seismic risk. The territory of Bulgaria (situated in the eastern part of the Balkan Peninsula) represents a typical example of high seismic risk area. Over the centuries, Bulgaria has experienced strong earthquakes. The strongest earthquakes reached magnitude 7.8 in southwestern Bulgaria, magnitude 7.5 in northeastern Bulgaria, and magnitude 7.0 in southern Bulgaria. Moreover, the seismicity of the neighboring countries, like Greece, Turkey, former Yugoslavia and Romania (especially Vrancea-Romania intermediate earthquakes), influences the seismic hazard in Bulgaria. In the present study earthquake scenarios for three Bulgarian cities (Sofia, Rousse and Vratsa) are presented. The scenarios were generated using deterministic approach that was applied in the European project Risk-EU (2001-2004). Such scenarios are intended as a basic input for developing detailed earthquake damage scenarios for the cities and can be used in earthquake-safe town and infrastructure planning.
\end{abstract}

Keywords: Historical earthquakes, earthquake safety, geotechnical zonation, seismic hazard, deterministic scenario, earthquake scenario.

\section{Introduction}

Earthquakes are the most deadly of the natural disasters affecting the human environment; indeed catastrophic earthquakes have marked the whole human history, accounting for $60 \%$ of worldwide casualties associated with natural disasters. Earthquakes are the expression of the continuing evolution of the Earth planet and its surface. Earthquakes adversely affect large parts of the Earth. Global seismic hazard and 
vulnerability to earthquakes are increasing steadily as urbanization and development occupy more areas that are prone to effects of strong earthquakes. Additionally, the uncontrolled growth of mega cities in highly seismic areas around the world is often associated with the construction of seismically unsafe buildings and infrastructures, and undertaken with an insufficient knowledge of the regional seismicity peculiarities and seismic hazard. The assessment of seismic hazard and generation of earthquake scenarios is the first link in the prevention chain and the first step in the evaluation of seismic risk. The implementation of earthquake scenarios into the policies for seismic risk reduction will allow focusing on the prevention of earthquake effects rather than on intervention following the disasters.

Bulgaria, situated in the Balkan Region as part of the Alpine-Himalayan seismic belt is characterized by high seismicity, and is exposed to a high seismic risk. Over the centuries, Bulgaria has experienced strong earthquakes. In historical aspect, several earthquakes with magnitude $M \geq 7$ are observed, the first well documented is of $1^{\text {st }}$ century BC in NE Bulgaria affecting the Black Sea coast. For the study purposes, it is worth to mention the 1818 (VIII-IX MSK) and the $1858\left(M_{S}=6.3, I_{0}=\right.$ IX MSK) earthquakes that occurred near the town of Sofia. At the beginning of the $20^{\text {th }}$ century (from 1901 to 1928) five earthquakes with magnitude larger than or equal to $M_{S}=7.0$ occurred in Bulgaria. Impressive seismic activity developed in the SW Bulgaria during 1904-1906. The seismic sequence started on 4 of April 1904 with two catastrophic earthquakes within 23 minutes (the first quake with $M_{S}=7.3$ considered as a foreshock and the second, the main shock, with $M_{S}=7.8$ and $I_{0}=\mathrm{X}$ - one of the Europe's strongest earthquakes in $20^{\text {th }}$ century). Along the Maritsa valley (central part of Bulgaria), a sequence of three destructive earthquakes occurred in 1928. However, no such large earthquakes occurred in Bulgaria since 1928. The 1986 earthquake of magnitude $M_{S}=5.7$ occurred in the central northern Bulgaria (near the town of Strazhitsa) is the strongest quake after 1928. Moreover, the seismicity of the neighboring countries, like Greece, Turkey, former Yugoslavia and Romania (especially Vrancea-Romania intermediate earthquakes involving the noncrustal lithosphere), influences the seismic hazard in Bulgaria.

In the present study, deterministic scenarios (expressed in seismic intensity) for the cities of Sofia, Rousse and Vratsa are presented. The work on scenarios was guided by the perception that usable and realistic (also in the sense of being compatible with seismic histories of cities that are often several centuries long) ground motion maps had in the end to be produced for urban areas. The wide differences in earthquake hazard exposure, local geological and geotechnical characteristics, and urban features of the cities has made it necessary to apply different alternative of the approach, sufficiently flexible to account for the basic factors in different situations. 
The work presented for the city of Sofia is part of the Bulgarian work carried out in the Risk EU Project (2001-2004) funded by the European Economic Commission in the framework of the Fifth Research and Technological Development Program "Energy, Environment and Sustainable Development." Scenarios for the cities of Rousse and Vratsa were generated within the project (PP) "Estimation of Seismic Risk and Potential Damages (Caused by Destruction of Building and Infrastructure in the Urban Area) on the Base of GIS as an Element of Integrated National Database."

\section{Approaches Used for Developing Earthquake Scenarios}

The approaches adopted for developing ground motion hazard maps (earthquake scenarios) — both deterministic and probabilistic — should include the following stages:

1. Compilation of regional seismotectonic database (region within a radius of $150 \mathrm{~km}$ surrounding the considered urban area);

2. Analysis of regional seismotectonics (identification of the tectonic feature(s) capable of generating the scenario earthquake with the associated magnitude level), and representation of seismic sources for the different methods of analysis;

3. Seismotectonic zonation, the aim of which is the relationships between seismicity and active geological structures, forms an indispensable part of seismic-hazard assessment;

4. Geotechnical characterization of the studied area;

5. Seismic hazard assessment;

6. Cross-validation of the local ground-shaking representations obtained through the use of different methods.

A flowchart showing the main ingredients of the approaches for developing earthquake scenarios and their mutual relationships is illustrated in Figure 1.

\section{Deterministic Seismic Hazard Evaluation for the City}

By deterministic scenario it is meant a representation of the severity of ground shaking over an urban area, using one or more hazard descriptors. Such representation can be obtained:

- Either from the assumption of a "reference earthquake" specified by a magnitude or an epicentral intensity, associated to a particular earthquake source(e.g., a fault, a point, a crustal volume);

- Or, directly, showing values of local macroseismic intensity or of instrumentally measured parameters (if available) generated by a damaging, real earthquake of the past. 


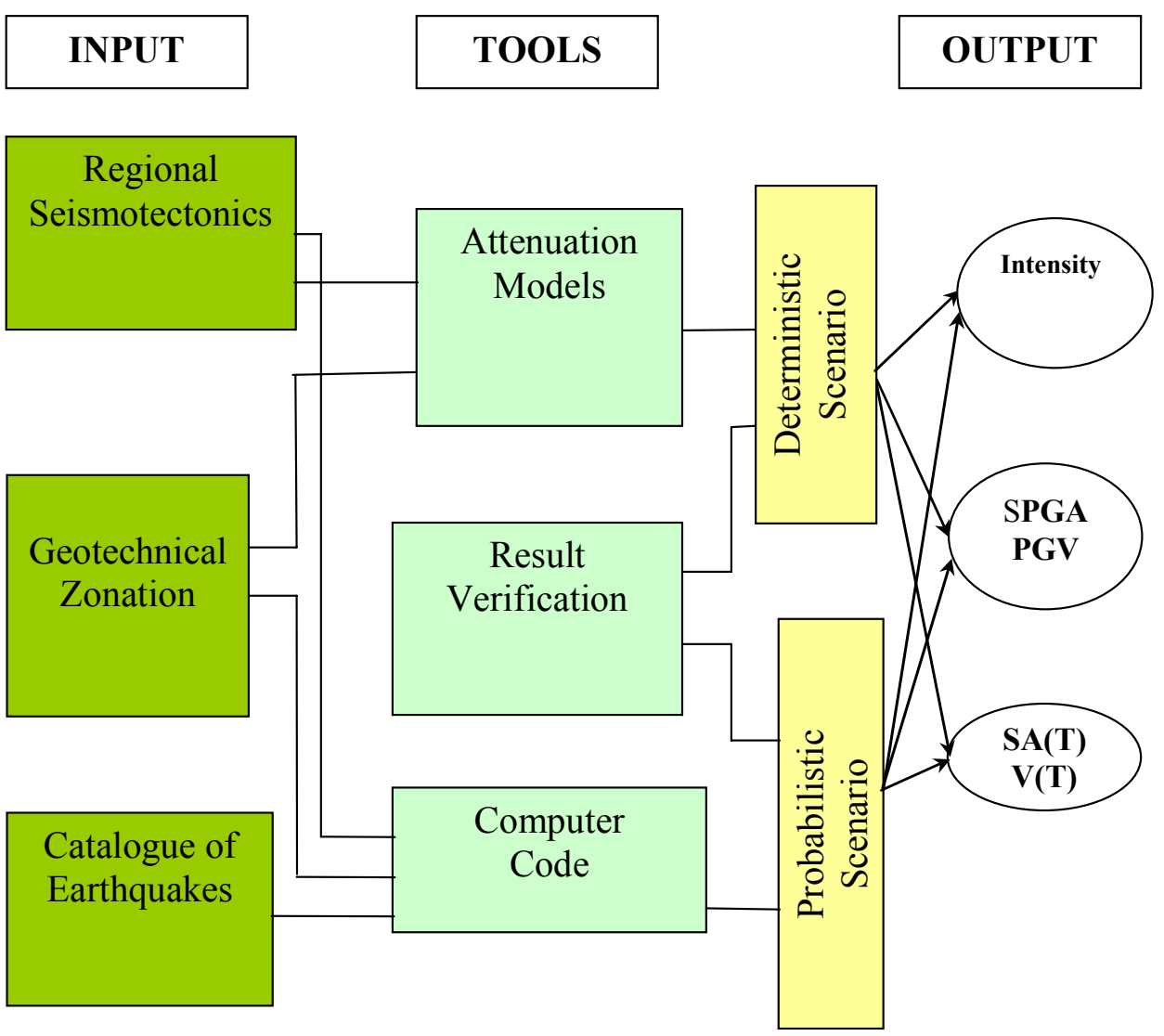

Figure 1: Flowchart Showing the Main Ingredients of the Approach for Earthquake Scenario Generation.

In the first case, the local ground shaking levels typically need to be computed through attenuation relations for the selected hazard parameter(s). Instrumental parameters, such as response spectral ordinates, should preferably be estimated through the local attenuation relationships. In the second case, the most common situation is that of a single or few intensity value(s) that concisely describes the severity of the effects on the built environment caused by the historical earthquake selected as representative.

Perhaps the single most important feature of the approach is that the deterministic scenario must be consistent with the seismic history of the city. Thus, the reference event for the deterministic scenario should be the "true" maximum historical earthquake that affected the city or, stated differently, the use of seismotectonic criteria to "shift" the epicenters of historical earthquakes nearest to city to derive 
Maximum Credible Earthquake effects, or the like, is discarded.

The scenario maps must include soil amplification effects. The standard option for doing this is through the geotechnical zonation of the considered urban area.

If in its history the city considered has been exposed to earthquakes of significantly different intensity, e.g., both destructive and damaging events, two different deterministic scenarios are desirable. However, for one given scenario the preferred hypothesis for the seismic source should be clearly indicated and justified.

Finally, to provide an indirect estimate of the return periods associated with the ordinates of the deterministic scenario for a representative city site, the corresponding response spectrum should be compared (possibly on the same plot) with the probabilistic response spectra for different return periods (presumably).

\section{Probabilistic Seismic Hazard Assessment for the City}

Seismic hazard is the probability that various levels of strong ground motion will be exceeded during a specified time period at a site. The ground motion levels may be expressed in terms of peak ground acceleration (velocity, displacement) and/or peak response spectral amplitudes for a range of frequencies. Probabilistic techniques utilize all the details and parameters of the regional seismotectonic model. The analysis is often summarized with a seismic hazard curve, which shows annual probability of exceedance (or frequency of exceedance) versus ground motion amplitude.

The formal procedure for probabilistic calculations taking account of spatial and temporal uncertainty in the future seismicity was presented by Esteva ${ }^{2}$ and Cornell. ${ }^{3}$ The probabilistic method of seismic hazard analysis, as it is currently understood, was presented by Cornell, ${ }^{4}$ and by Merz and Cornell. ${ }^{5}$

Two types of uncertainty are defined in seismic hazard analysis - random (aleatory) and modeling (epistemic). Distinction between the two types of uncertainty has emerged as an important issue in the proper estimation of seismic hazard. Nowadays, it has become established practice that the ground motion variability is an integral and indispensable part of PSHA. ${ }^{6}$ Modern methods of seismic hazard analysis incorporate uncertainties into the analysis to assess their impact on the estimate of the expected level of seismic hazard as well as the uncertainty in that estimate. The probability of exceeding of various levels of ground motions are assessed by using computer software, such as EQRISK, ${ }^{7}$ SEISRISK I, II, III, ${ }^{8}$ etc.

The main steps involved in the seismic hazard analysis are the following:

1. Construction of seismic source model - each element of the model is represented as a seismic source (areal, volume, linear or point) with defined geometry and depth; 
2. Determination of seismicity parameters, such as magnitude frequency relationship, minimum magnitude, maximum magnitude and their uncertainties for each seismic source;

3. Designation of a ground motion attenuation relationship for each seismic source;

4. Selection of appropriate stochastic model of earthquake occurrence (Poisson, Markov, etc.);

5. Computation of seismic hazard curves with appropriate confidence levels such as to demonstrate how the data are scattered;

6. Sensitivity analysis.

Figure 2 presents a flow chart with the main stages in probabilistic seismic hazard analysis.

\section{Earthquake Scenarios}

\section{Earthquake Scenario for the City of Sofia}

The city of Sofia is the capital of Bulgaria. It is situated in the center of the Sofia area that is the most populated (the population is of more than 1.9 million inhabitants), industrial and cultural region of Bulgaria that faces considerable earthquake risk. The earthquakes that mainly influence the hazard in Sofia originate near the city. The available historical documents prove the occurrence of destructive earthquakes during the $15^{\text {th }}-18^{\text {th }}$ centuries in the Sofia area. ${ }^{9}$ Prior to the $19^{\text {th }}$ century Sofia was a small town, deeply inside the Ottoman Empire and only a few reports on earthquakes felt therein could be found. In $19^{\text {th }}$ century, the city of Sofia experienced two strong earthquakes: the 1818 earthquake with epicentral intensity $I_{0}=$ VIII-IX MSK and the 1858 earthquake with $I_{0}=$ IX-X MSK (recently revised value in terms of EMS98 proves to be the same). The 1858 earthquake caused heavy destruction in the town of Sofia and the appearance of thermal springs in the western part of the town. Interpretation of this earthquake (magnitude, affected area, etc.) is still subject to discussions mainly because of the scarcity of data (in 1858 Sofia's urbanized area was $2.8 \mathrm{~km}^{2}$ and the population was less than 15,000 inhabitants). During the $20^{\text {th }}$ century the strongest event that occurred in the vicinity of the city of Sofia is the 1917 earthquake with $M_{S}=5.3$ ( $I_{0}=$ VII-VIII MSK64). The earthquake caused a lot of damage in the town and changed the capacity of the thermal mineral springs in Sofia and the surrounding villages. The earthquake was felt in an area of $50,000 \mathrm{~km}^{2}$ and was followed by aftershocks, which lasted more than one year. ${ }^{10}$ No earthquakes with magnitude larger than or equal to 5 have been localized in the Sofia seismic zone since 1917 . The strongest event of recent years is the magnitude 4.3 quake in 1980 that occurred 


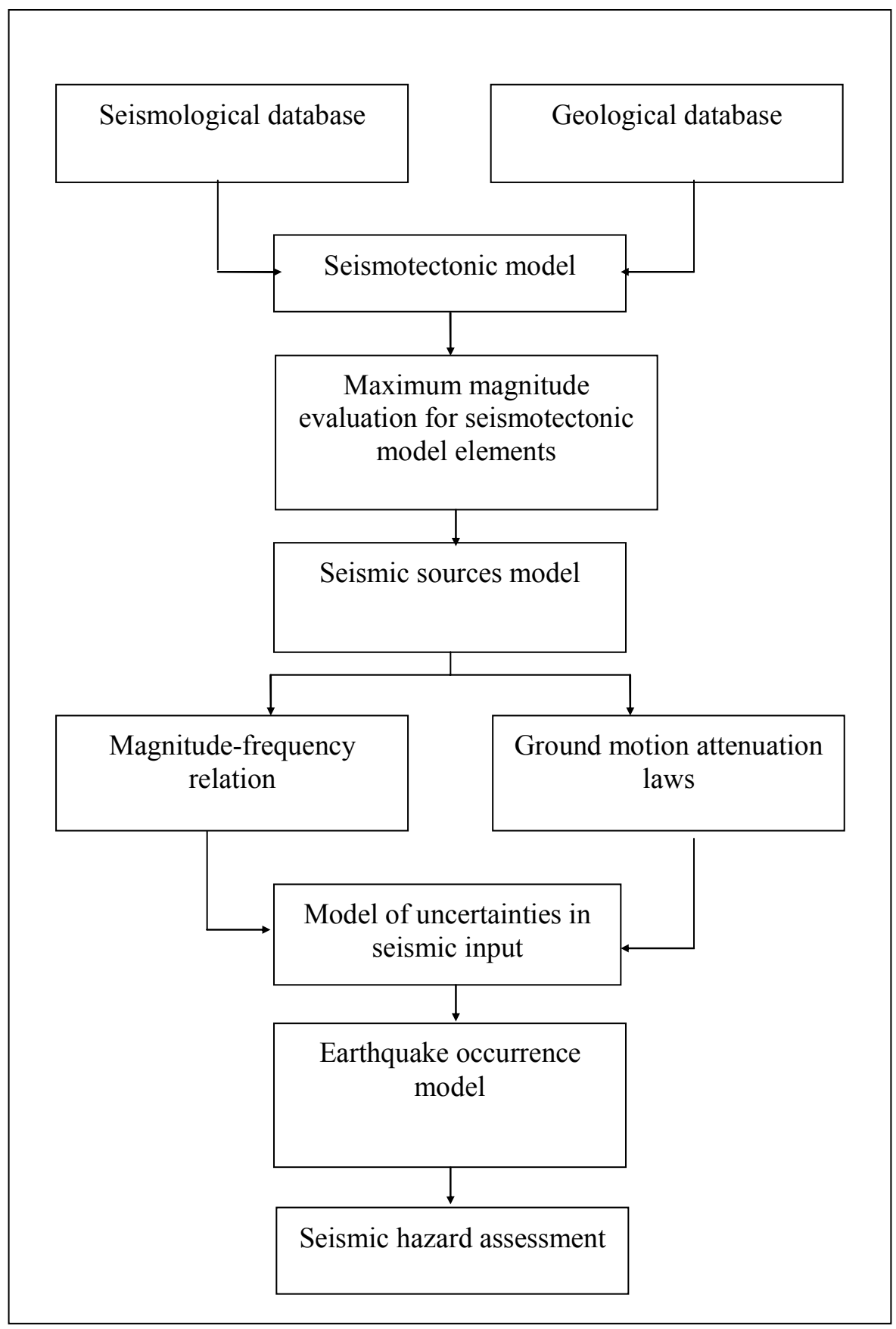

Figure 2: Flow Chart for Seismic Hazard Assessment. 
in the most northern part of the Sofia seismic zone at about $30 \mathrm{~km}$ from the city of Sofia. However, no such large earthquakes have occurred near the city of Sofia area since 1858, which may induce non-professionals to underestimate the earthquake risk.

The contemporary tectonic activity of the Sofia area is associated predominantly with marginal faults of Sofia graben. The boundaries of the graben are represented by SENW fault systems with expressive neotectonic activity. Earthquakes in the Sofia zone seem to be distributed along these fault systems, which have played an active role in the recent geodynamic evolution of the area. The western segments of marginal fault system appear to be the most probable source for earthquakes (such as the abovementioned 1818 and 1858 events, heavily damaging the city of Sofia). Thus, simplified source representation is adopted that consists of SE-NW trending (striking $\mathrm{N}$ $124^{\circ}$ ), normal fault at a minimum distance of $15 \mathrm{~km}$ from the center of the city.

Base of seismic history of Sofia, the 1858 earthquake ( $I_{0}=$ IX-X MSK64) was considered as responsible for the macroseismic intensity scenario. The available magnitude estimates of this earthquake are in the range 6.0-6.5. Therefore, the magnitude value of 6.3 and the maximum macroseismic intensity of IX-X MSK were used for intensity hazard scenario. The geotechnical soil properties of the Sofia municipal area were incorporated in the hazard evaluation by using the simplified geotechnical map for the city of Sofia shown in Figure 3.
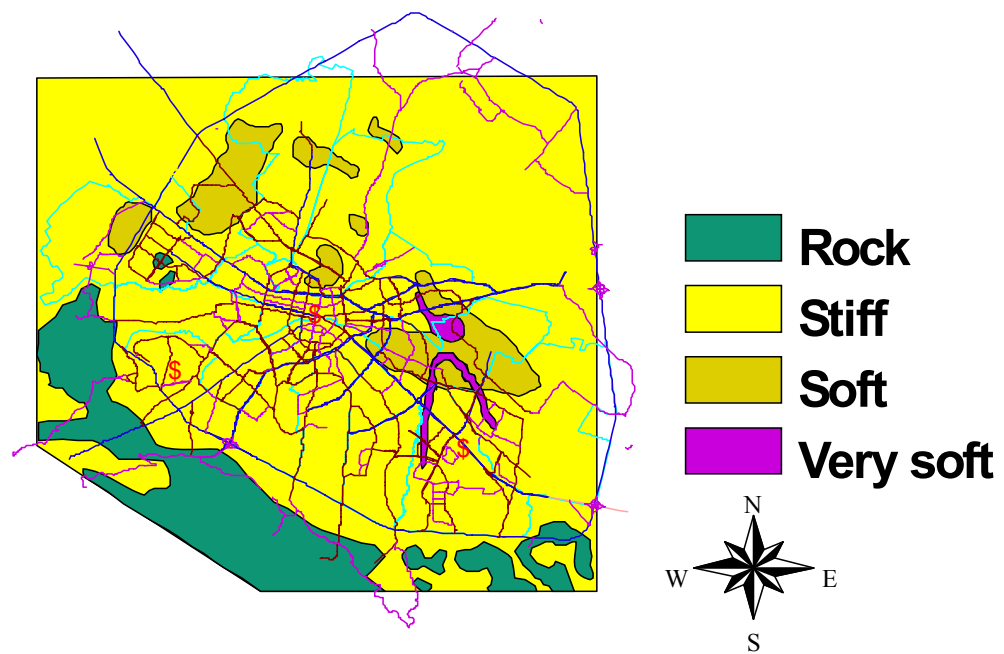

Figure 3: A Schematic Geotechnical Map for the Sofia Municipal Area Incorporated in Earthquake Scenario Generation. 
The intensity map was created using the generalized macroseismic model for earthquakes on the territory of Bulgaria developed by Glavcheva and colleagues. ${ }^{11}$ The intensity isoseismal is approximated to an ellipse in the modeling. The ellipse is defined by the following equations:

$$
\begin{aligned}
& \operatorname{Lg} Q(I, M)=c(I) * M+d(I) \\
& \operatorname{Lg}\left(a^{*} b^{2}\right)=c_{1}(I) * M+d_{1}(I) \\
& \operatorname{Lg}\left(b^{2} / a\right)=c_{2}(I) * M+d_{2}(I)
\end{aligned}
$$

where $M$ is earthquake magnitude; $I$ - macroseismic intensity; $Q$ - size of an ellipse at a fixed $I ; a$ and $b$ - semi-axes of an ellipse at a fixed $I ; c, c_{i}, d, d_{i}-$ empirical coefficients. The coefficients were determined on the basis of historical data for earthquakes in and near Bulgaria using the least squares method.

The estimated intensity field is presented in Figure 4 . The intensity values range between VII-VIII and IX and although a general decreasing trend with increasing distance from the source is obvious, a certain complexity in the spatial distribution arises because of the influence of soil conditions (as for example the amplification in the central part of the city). The amplification in the southwestern part of the city marks the area where in 1858 thermal spring appeared.

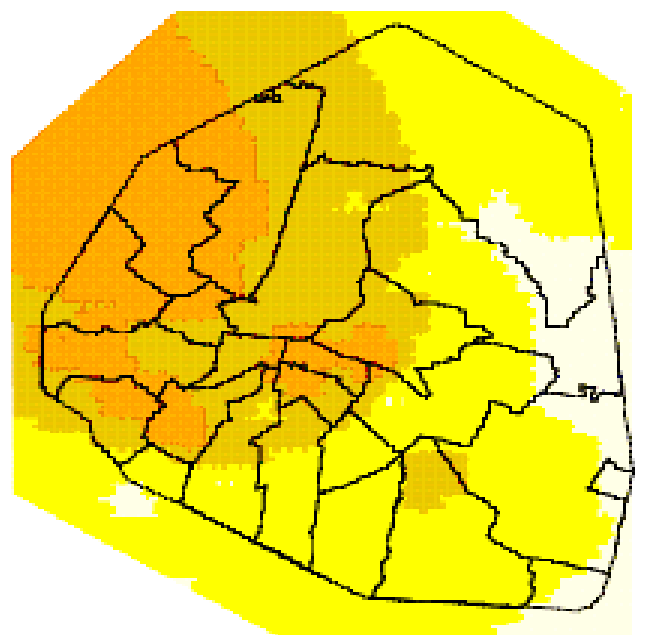

Intensity
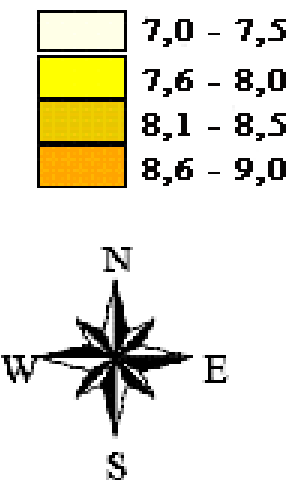

Figure 4: Earthquake Scenario for the City of Sofia (in Intensity). 


\section{Earthquake Scenario for the City of Rousse}

The city of Rousse is located on the right bank of the Danube river, in the firth of Rusenski Lom River. Its population is about 162,000 people. The city is an administrative, transport and tourist centre of Bulgaria.

The seismic history of Rousse shows that the risk for the city is mainly due to the influence of the intermediate quakes that occurred in the region of Vranchea (Romania). The generation of intensity scenario uses directly the intensity assessment of the strongest past earthquakes, felt in the city (these are the 1940 quake with $M=7.3$ and the 1977 quake with 7.2, both occurring in Vranchea, Romania). For both earthquakes, distribution of macroseismic effects along the city is estimated on the basis of documents available in the regional administration of "State Archive," Rousse, and the regional library "L. Karavelov." The geotechnical soil properties of the urban area were incorporated in the risk evaluation by using the simplified geological map for the city of Rousse.

The earthquake scenario for the city of Rousse is presented in Figure 5 (intensity scenario is generated within the project PP and presented in Report GFI, 2007). ${ }^{12}$

\section{Earthquake Scenarios for the City of Vratsa}

Vratsa is a city in northwestern Bulgaria, at the foothills of the Balkan Mountains. It is administrative centre of the Vratsa province. The city of Vratsa is a commercial and crafts centre and a railway junction. The municipal area of the city is inhabited by 80,040 people (as of 2004).

Seismic history of Vratsa shows that the strongest on-city seismic effects are caused by the 1904 earthquakes ( $M=7.3$ and $M=7.8$ ), which occurred in southwestern Bulgaria (Krupnik-Kresna region). The maximal observed intensity for the city of Vratsa is $I=6$ MSK.

The intensity scenario was generated from regional maps of maximum observed seismic intensity (over a sufficiently long period of time). Alternatively, an earthquake scenario was developed for predicted intensity for 1,000 year backwards period according to seismic zoning of Bulgaria. ${ }^{13}$ The geotechnical soil properties of the Vratsa municipal area were incorporated in the hazard evaluation by using the detail geotechnical map for the city of Vratsa.

The earthquake scenarios for the city of Vratsa are presented in Figure 6 (maximum observed seismic intensity) and Figure 7 (predicted intensity for 1,000 year period). Both intensity scenarios are generated within the project PP and presented in the Report of GFI. ${ }^{14}$ 


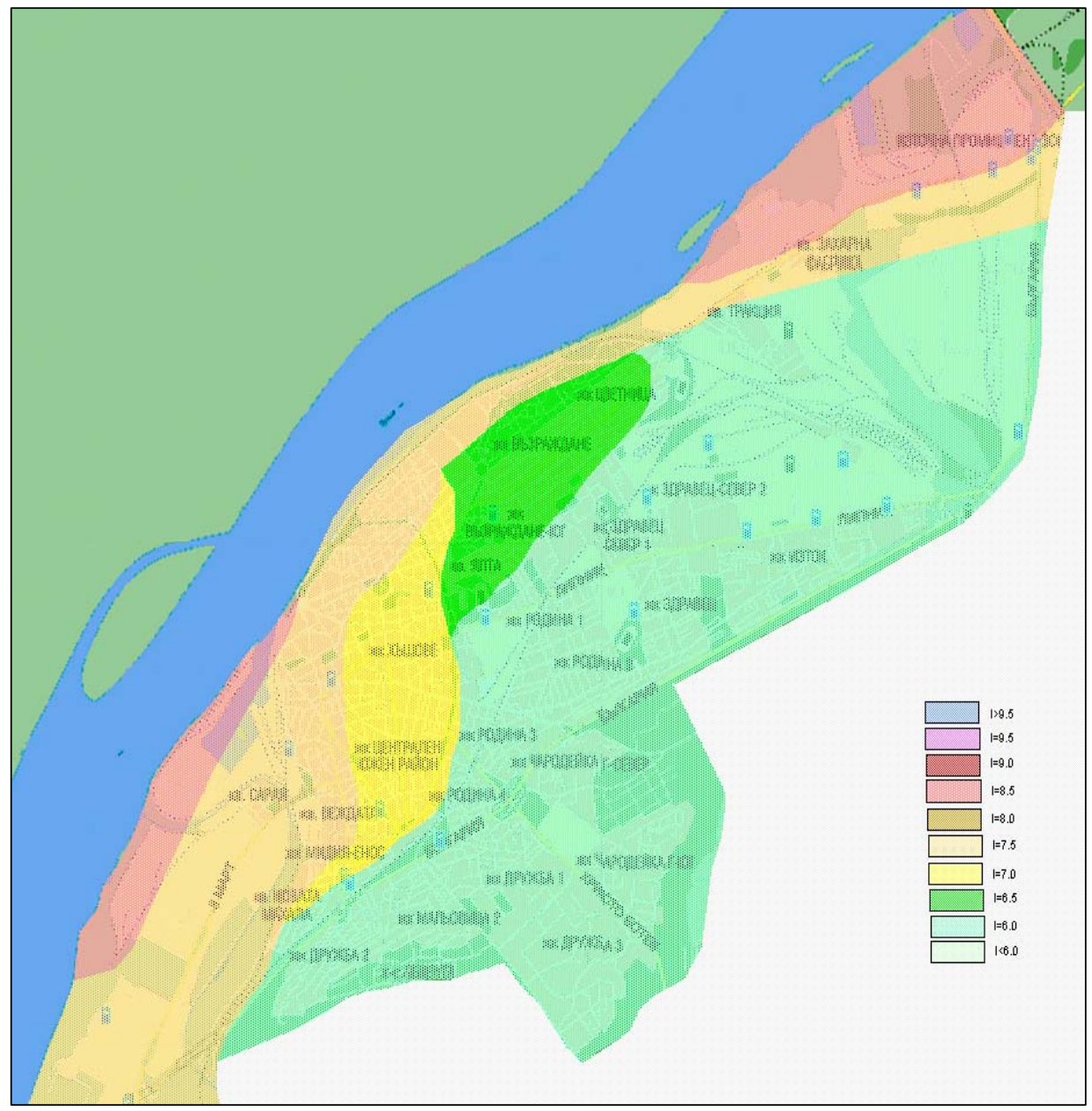

Figure 5: Earthquake Scenario for the City of Rousse (in Intensity). 


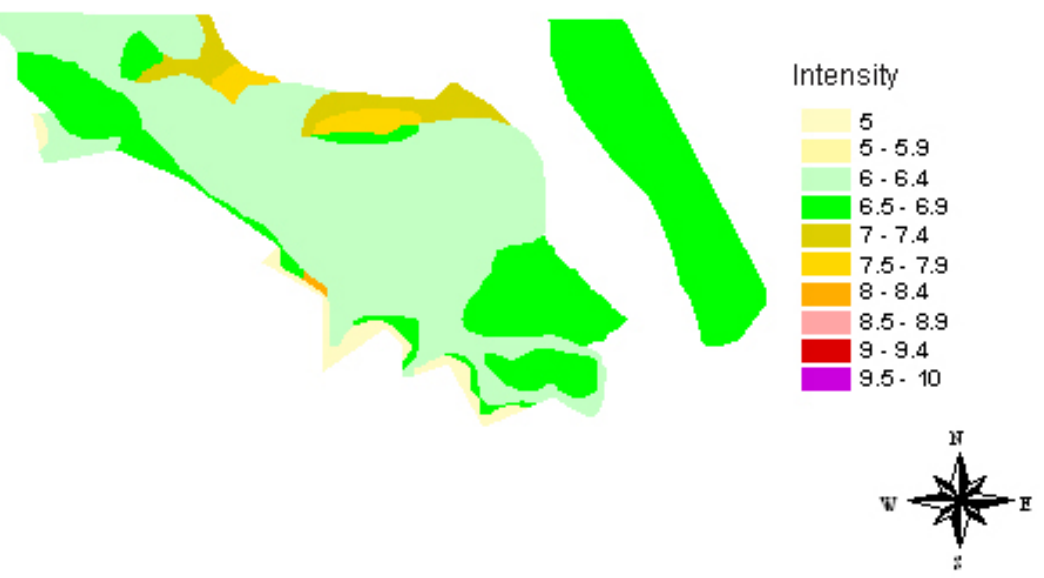

Figure 6: Earthquake Scenario for the City of Vratsa (Maximum Observed Intensity $I=6 \mathrm{MSK})$.

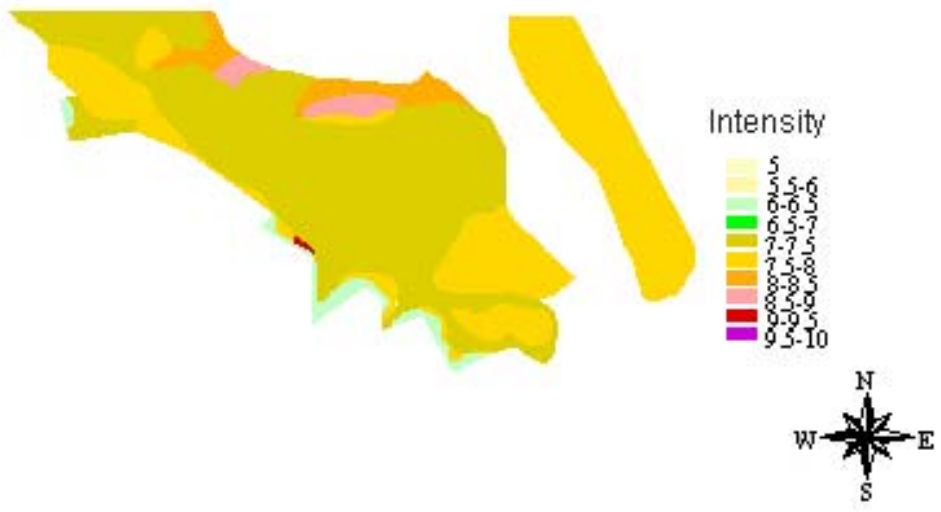

Figure 7: Earthquake Scenario for the City of Vratsa - Predicted Intensity for 1,000 year period, $I=7 \mathrm{MSK}$.

\section{Notes:}

1 GFI and CLSMEE, WP2: Seismic Hazard Assessment and Ground Motion Scenarios for the City of Sofia, Report, Contract: EVK4-CT-2000-00014.

2 Luis Esteva, "Criteria for the Construction of Spectra for Seismic Design," (paper presented at the Third Panamerican Symposium on Structures, Caracas, Venezuela, 1967); Luis Esteva, Bases para la formulacio'n de decisiones de diseño sl 'smico, Ph.D. Thesis (Mexico City: Universidad Nacional Auto'noma de Mexico, 1968). 
3 Carl Allin Cornell, "Engineering Seismic Risk Analysis," Bulletin of the Seismological Society of America 58, no. 5 (October 1968): 1583-1606.

4 Carl Allin Cornell, "Probabilistic Analysis of Damage to Structures under Seismic Loads," in Dynamic Waves in Civil Engineering, ed. D.A. Howells, I.P. Haigh, and C. Teylor (New York: John Wiley\&Sons, 1971), 473-488.

5 Hanz A. Merz and Carl Allin Cornell, "Seismic Risk Based on a Quadratic Magnitude-frequency Law," Bulletin of the Seismological Society of America 63, 6 (1973), 1999-2006.

6 Julian J. Bommer and Norman A. Abrahamson, "Why Do Modern Probabilistic SeismicHazard Analyses Often Lead to Increased Hazard Estimates?" Bulletin of the Seismological Society of America 96, no. 6 (2006), 1967-1977.

7 Robin K. McGuire, FORTRAN Computer Program for Seismic Risk Calculations, OpenFile Report 76-67 (United States Department of the Interior, Geological Survey, 1976), 190 .

8 Bernice Bender and David M. Perkins, "Seisrisk II: A Computer Program for Seismic Hazard Estimation," Open-file report 82-293 (United States Department of the Interior, Geological Survey, 1982).

9 Spass Watzof, Earthquakes in Bulgaria during XIX Century (Sofia: Central Meteorological Station, 1902), pp. 93 (in Bulgarian and French).

${ }^{10}$ K. Kirov, "Contribution to the Study of Earthquakes in the Sofia Region," Annals of Main Department for Geological and Mining Research 5 (1952): 407-440 (in Bulgarian).

${ }^{11}$ Rumiana Glavcheva, Stella Simeonova, and Dimcho Solakov, "A Generalized Macroseismic Model of the High Intensities Fields for Bulgaria," Bulgarian Geophysical Journal 8, no. 3 (1982): 77-83; Rumiana Glacheva, Stella Simeonova, Tzenka Hristova, and Dimcho Solakov, "Generalized Isoseismals of the High Intensities for Earthquakes in Bulgaria," Bulgarian Geophysical Journal 9, no. 3 (1983): 69-77.

${ }^{12}$ PP: Estimation of Seismic Risk and Potential Damages (Caused by Destruction of Building and Infrastructure) (Bulgarian Academy of Sciences: Geophysical Institute, 2007).

${ }^{13}$ E. Bonchev, V. Bune, L.Christoskov, J. Karagjuleva, V. Kostadinov, G. Reisner, S. Rizhikova, N. Shebalin, V. Sholpo, D. Sokerova, "A Method for Compilation of Seismic Zoning Prognostic Maps for the Territory of Bulgaria," Geologica Balkanica, 12, no. 2 (1982), 2-48.

${ }^{14}$ PP: Estimation of Seismic Risk and Potential Damages.

DIMCHO SOLAKOV is Deputy Director of Geophysical Institute, Bulgarian Academy of Sciences. Education: 1988: Ph.D. in Physics, Seismological Department, Geophysical Institute of Bulgarian Academy of Sciences, Bulgaria. Research interests: earthquake source kinematics and dynamics, seismic hazard analysis, statistical methods in seismology, real time data acquisition and processing. He has 80 publications and 143 citations in national and international journals. He is a reviewer for national and international journals and government institutions. Professional Awards: Insignia of honour, received from BAS, "Scientific research in Earth sciences" received from BAS (2000). Participation in international projects: Task group 1, Permanent Coordinating Committee for Earthquake Risk Reduction in the Balkan Region; 
PLATO-1, MRDNET; EC projects: EVK4-CT-2000-00014 RISK-UE; EVR1-CT-2000-40007 "MEREDIAN-2."

STELLA SIMEONOVA is Ass. Professor in Seismological Department of Geophysical Institute, Bulgarian Academy of Sciences. Education: 1999: Ph.D. in Physics, Seismological Department, Geophysical Institute of Bulgarian Academy of Sciences, Bulgaria. Research interests: Earthquake source-kinematics and dynamics, seismic hazard analysis, statistical methods in seismology. She has 60 publications and 98 citations in national and international journals. She is a reviewer for national and international journals and government institutions. Professional Awards: "Scientific research in Earth sciences" received from BAS (2000). Participation in international projects: Task group 1, Permanent Coordinating Committee for Earthquake Risk Reduction in the Balkan Region; PLATO-1, MRDNET; EC projects: EVK4CT-2000-00014 RISK-UE; EVR1-CT-2000-40007 "MEREDIAN."

LUDMIL CHRISTOSKOV is Professor in Seismological Department of Geophysical Institute, Bulgarian Academy of Sciences. Education: 1982: Doctor of Science, Seismological Department, Geophysical Institute of Bulgarian Academy of Sciences. Research interests: energy classification of earthquakes, dynamics of seismic waves and sources, seismic zoning and seismic hazard assessment, development of instrumental observation methods in seismology, data acquisition and processing. He has 280 publications and over 800 citations in national and international journals. He is a reviewer for national and international journals and government institutions. Professional Awards: "Scientific research in Earth sciences" received from BAS (2000). Participation in international projects: Task group 1, Permanent Coordinating Committee for Earthquake Risk Reduction in the Balkan Region; PLATO-1, MRDNET; EC projects: EVK4-CT-2000-00014 RISK-UE; EVR1-CT-2000-40007 "MEREDIAN-2."

IRENA ALEKSANDROVA is Research scientist in Geophysical Institute of Bulgarian Academy of Sciences. Education: 1989, Master Degree in Geology, University of Mining and Geology "Sv. Ivan Rilski." Research interests: Historical earthquakes, macroseismic research, data processing, hazard assessment. Participations in projects: "Monitoring of seismicity and analysis of seismic processes in the seismic active zones on the territory of Bulgaria and surrounding areas," Recording, analysis, processing and interpretation of seismological information from Local Seismic Network on the NPP "Kozloduy" area.

GERGANA GEORGIEVA is a PhD Student in Geophysical Institute of Bulgarian Academy of Sciences. Education: 2005 Masters Degree, University of Sofia "Sv. Kliment Ohridski." Research interests: signal processing, real time data acquisition. Participation in projects: EMIRA, "Monitoring of seismicity and analysis of seismic processes in the seismic active zones on the territory of Bulgaria and surrounding areas," Recording, analysis, processing and interpretation of seismological information from Local Seismic Network on the NPP "Kozloduy" area.

ILIANA POPOVA is a PhD Student in Geophysical Institute of BAS. She works as a seismologist in NOTSSI. Education: 2005 Masters Degree, University of Sofia "Sv. Kliment Ohridski." Research interests: earthquake mechanisms, historical earthquakes, real time monitoring of the seismicity. Participations in projects: "Monitoring of seismicity and analysis of seismic processes in the seismic active zones on the territory of Bulgaria and surrounding areas," Recording, analysis, processing and interpretation of seismological information from Local Seismic Network on the NPP "Kozloduy" area. 